\title{
Development and Impact of the Egyptian Climatic Conditions on Flexible Pavement Performance
}

\author{
Maha A. Elshaeb, Sherif M. El-Badawy ${ }^{*}$, El-Sayed A. Shawaly \\ Graduate Student, Public Works Engineering Department, Faculty of Engineering, Mansoura University, Mansoura, Egypt \\ *Corresponding author: sbadawy@mans.edu.eg
}

Received May 04, 2014; Revised June 03, 2014; Accepted June 05, 2014

\begin{abstract}
Pavements are subject to environmental conditions, which affect the performance of both flexible and rigid pavements. The current flexible pavement design system in Egypt relies primarily on the 1993 American Association of State Highway and Transportation Officials (AASHTO) Design Guide. The method has many limitations. One of the serious limitations is the empirical drainage layer coefficients. These coefficients in addition to the seasonal variation of the roadbed resilient modulus are the only environmental consideration in the method. The newly AASHTO released production version of the Mechanistic-Empirical Pavement Design Guide (MEPDG) which is called AASHTOWare Pavement ME Design was developed to overcome the limitations inherent in the AASHTO 1993 method. Unlike the AASHTO 1993 method, Pavement ME Design method considers the variation in moisture and temperature on the mechanical properties of the pavement layers. Thus, the main objective of this study was to develop the climatic data to facilitate the implementation of Pavement ME Design in Egypt and study its influence on the pavement performance. Pavement ME required climatic data which are the hourly air temperature, precipitation, wind speed, sunshine and relative humidity were collected for 16 climatic locations distributed all over Egypt for four years. The quality of the data was checked and verified and the data was transformed to the format required by the software. A typical flexible pavement section was simulated using the ME design at the 16 different climatic locations and the performance predicted using the ME Design was analyzed. The performance indicators predicted by Pavement ME are rutting, alligator fatigue cracking, longitudinal cracking, thermal cracking, and International Roughness Index (IRI). Results showed that the pavement performance is significantly affected by the change in the climatic data. As expected, for Egypt, the most significant influence was on the predicted rutting of the Asphalt layer.
\end{abstract}

Keywords: AASHTOWare, MEPDG, AASHTO 1993, climate, cracking, rutting, performance

Cite This Article: Maha A. Elshaeb, Sherif M. El-Badawy, and El-Sayed A. Shawaly, "Development and Impact of the Egyptian Climatic Conditions on Flexible Pavement Performance." American Journal of Civil Engineering and Architecture, vol. 2, no. 3 (2014): 115-121. doi: 10.12691/ajcea-2-3-4.

\section{Introduction}

Pavements are built to sustain traffic and environmental conditions throughout their service lives. In designing durable pavements, several factors are assessed and one such primary factor is the climate of the proposed highway location which can have a significant impact on pavement performance [1]. The most important environmental factors that significantly affect the mechanical behavior of all pavement layers and thus the overall performance of the pavement system are temperature and moisture. At low temperatures, asphalt becomes hard and brittle and at extremely low temperatures, asphalt layers are prone to thermal and fatigue cracking. On the contrary, at high temperatures, asphalt becomes soft and more viscous and thus it is more prone to rutting. For concrete pavements, thermal gradient between the top and bottom of the concrete slab can cause curling stresses [2].
Moreover, temperature and moisture fluctuations affect the behavior of unbound layers and subgrade soils. An increase in moisture content reduces the load carrying ability (resilient modulus) of the unbound layers and subgrade soils.

The current flexible pavement design system in Egypt is adopted from the 1993 American Association of State Highway and Transportation Officials (AASHTO) Design Guide. This design method is empirical in nature. It is based on the results of the AASHO Road test which was conducted in the late 1950's and early 1960's. AASHTO 1993 method has many limitations. One of the significant limitations is the use of the empirical drainage layer coefficients $\left(\mathrm{m}_{\mathrm{i}}\right)$ to express the influence of the moisture on the unbound layers. The seasonal variation of the roadbed resilient modulus and the drainage layer coefficients, are the only environmental consideration in the method. The newly AASHTO released production version of the Mechanistic-Empirical Pavement Design Guide (MEPDG) which is called AASHTOWare Pavement ME Design was developed to overcome the limitations inherent in the AASHTO 1993 method. It is a 
very advanced tool for the analysis and design of new and rehabilitated flexible and rigid pavement structures. It mechanistically calculates the structural responses (stresses, strains, and deflections), within a pavement system [3]. Moisture and temperature variations within the pavement structure are calculated internally using the Enhanced Integrated Climatic Model (EICM). Pavement distresses and roughness are then predicted from the mechanistically calculated strains and deformations, using statistical (empirical) transfer functions which can be calibrated to specific conditions.

The current version of the software includes a comprehensive climatic database from 851 weather stations throughout the United States with at least 9 years of historical climatic data [4]. The required climatic data are the hourly air temperature, wind speed, sunshine, precipitation, and humidity. The depth to ground water table is also a required input. The climatic data required for this method are massive and need to be in a specific format.

\section{Objectives}

The main objective of this study is to develop the climatic data files for facilitating the implementation of the AASHTOWare Pavement ME Design in Egypt. The current investigation also extends to study the influence of the Egyptian climate on the performance of flexible pavements in Egypt.

\section{Literature Review}

Currently many agencies in the U.S. and Canada as well as many countries in the world are trying to implement the Pavement ME Design. However, one of the difficulties associated with its implementation is the amount and level of required inputs. In addition, the local calibration of the performance prediction models is another difficulty. Literature search showed that for a successful MEPDG implementation, a comprehensive input database for material characterization, traffic, and climate should be established [5]. Moreover, for more accurate and less biased predictions, distress prediction models should be locally calibrated based on the local conditions [5]. For implementation of MEPDG in Canada, it was reported that out of 232 weather stations, only 206 were found to have sufficient data as required by the design method [6]. Meagher et al presented a methodology to assess forecasted climate change impacts on pavement deterioration using MEPDG [7]. The influence of climate change on pavement performance predicted using MEPDG was also studied by Li et al [1]. The correlations between the different climatic factors and distress parameters for the state of Arkansas was assessed by the MEPDG [8]. Zaghloul et al evaluated the potential impacts of the accuracy of EICM predictions on MEPDGpredicted damage and pavement service life [9]. For the MEPDG implementation/calibration efforts, many states used the MEPDG built-in climatic data files within the state and the ones from neighboring states that are in close proximity [5,10,11,12,13].
Many literature studies reported problems with the quality of collected climatic data such as missing some weather data because of different reasons. Some of these reasons are maintenance of the weather station, malfunction, or extreme weather [3,4,14,15]. In these cases, researchers used different techniques to account for the missing weather data. To create continuous hourly weather data for MEPDG, Ley et al used the average of the weather data from the hours immediately before and after the missing data points for missing data of less than 3 hours in a row [14]. When less than two days in a row of data was missing, the missing data was calculated as the average of the value from the same hours on the days before and after the missing data points. When more than two days of data in a row was missing, the missing data was calculated from the average of the weather values from the same date and time of other available years of that weather station. When these longer periods of data were missing, the average of the values from the remaining year's data was used. The MEDPG manual and manual of practice recommend the use of virtual weather station instead of only one weather station [3,4]. Multiple weather stations (virtual station) are recommended because of the possibility of any missing data and errors in the database for an individual station. These virtual weather stations are created internally in the program by the interpolation of the climatic data from the multiple stations selected by the user. The virtual weather stations are also recommended if the project location is far from actual weather stations.

Dzotepe and Ksaibati used virtual weather stations created by the MEPDG from interpolation using two different methods to investigate and statistically analyze its adequacy on pavement design and performance in the state of Wyoming [16]. Each of the output performance results have been analyzed using the actual weather stations, virtual stations generated from interpolation of all available neighboring stations, and also by interpolation using similar elevations of +/-150 m difference. The actual output results generated were compared with results generated by the virtual stations. The researchers reported minimal variability between actual and virtual climate information except for the freezing index. They also reported minimal variability in performance parameters at the different locations except for transverse cracking.

Delgadillo et al developed an initial climatic database comprising of 17 weather stations across Chili [15]. They also studied the sensitivity of the distress predictions for the Chilean weathers. An initial database was developed using the available hourly data in the country. Considering the limited availability of hourly climatic data, the researches proposed different methods for the completion of the missing data. The used sinusoidal-exponential model for computing the hourly temperatures from the minimum and maximum daily temperatures. The researchers also presented an exponential model for hourly humidity based on maximum and minimum daily humidity. They reported that linear interpolation between the available hours with data for wind speed and cloud cover was enough to complete the hourly information for these variables. The researchers reported very accurate predicted distresses using these models compared with the predictions using the real hourly weather data. The developed models were found useful for validating the 
existing weather stations and detect inaccuracies and errors in the recorded hourly data.

Breakah et al investigated the importance of accurate climatic data [17]. They used built-in MEPDG climatic files and others developed based on historical information for counties in the state of Iowa to compare the pavement performance. The authors reported higher rutting for the northern part of the state, lower thermal cracking, and lower IRI from climatic files that were interpolated (virtual stations) from the data available within MEDPG as compared to the developed historical climatic files.

Heitzman et al developed climatic data files for MEPDG implementation in the state of Mississippi [18]. They used historic climatic files with hourly data from 23 Automated Surface Observation System (ASOS) and Automated Weather Observation Service (AWOS) and daily data from over 100 Cooperative Observer Program (COOP) sources combined to generate 40-year historic climatic data files for the 82 counties in Mississippi. They stated that the most difficult part about assembling climatic data files for MEPDG is the hourly data required. The authors utilized a simple linear temporal interpolation to predict the missing hourly data. The authors also studied the impact of three different climatic inputs (MEPDG built-in climatic files, developed historic climatic files, and virtual climatic files) on the performance of typical pavement types in Mississippi. Their results showed different performance.

\section{Climatic Data Collection Processing}

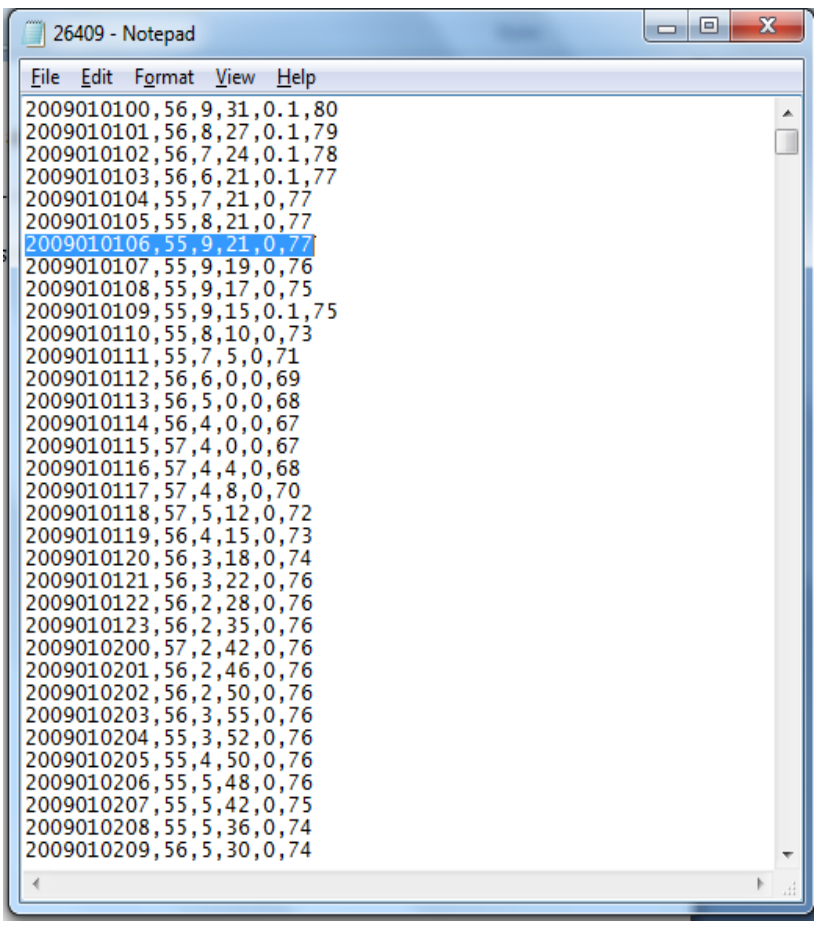

Figure1. Format of the climatic data files as required by the software

Significant effort was put into collecting the historical climatic data from the original source; Egyptian Meteorological Authority [19]. However, it was found that such process is very costly. A one year of historical climatic data for only one site would cost approximately 4500 Egyptian Pound (LE). This means 288,000 LE for four years and 16 climatic sites. In addition, the data will not be in the format directly usable by the software. Therefore, the data was collected from World Weather on Line [20]. This website has the required climatic data but for every three hours, not hourly as required by the ME Design software. Thus, a simple linear interpolation had to be conducted to convert this data into hourly data. A simple excel sheet was designed to perform the interpolation and convert the data into the required software format as well. A text file with an extension ".hcd" was created for each climatic location as required by the software. The data contained in each climatic file are: date (YYYY/mm/dd/hr), air temperature $\left({ }^{0} \mathrm{~F}\right)$, precipitation (in), wind speed (mile/h), sunshine (percentage), and relative humidity (percentage) as shown in Figure 1. The required climatic data was collected for 16 climatic locations covering the populated areas in Egypt. Figure 2 shows the distribution of the 16 selected climatic weather stations which cover the different environmental conditions in Egypt.

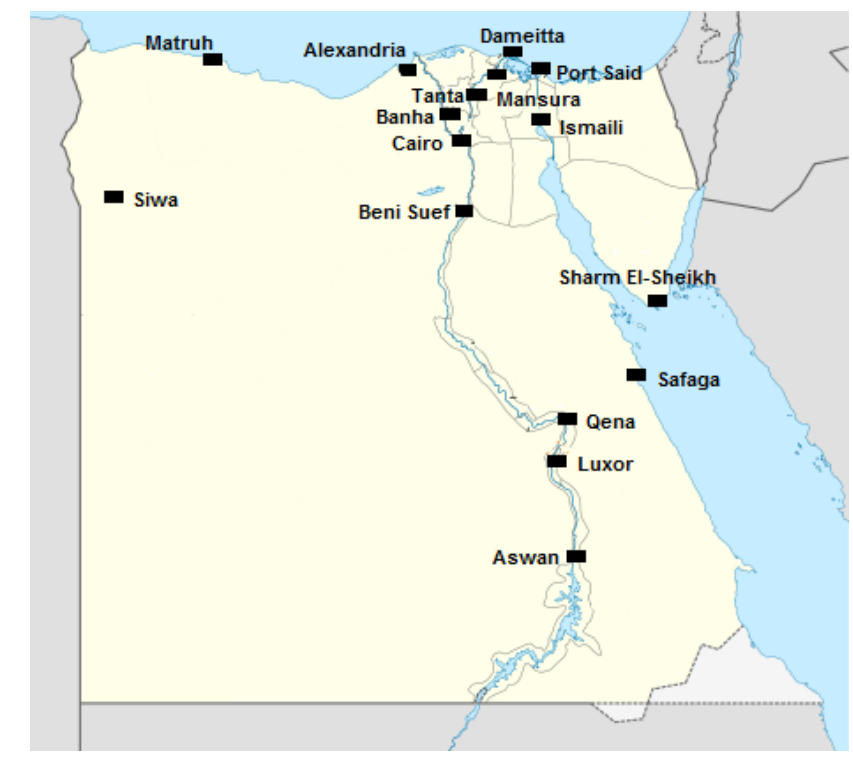

Figure 2. Distribution of the selected wweather sstations in Egypt

Table 1. Longitude, latitude, and eelevation of the selected weather stations in Egypt

\begin{tabular}{|c|c|c|c|}
\hline City & $\begin{array}{c}\text { Longitude } \\
\text { Degree. Minute }\end{array}$ & $\begin{array}{c}\text { Latitude Degree. } \\
\text { Minute }\end{array}$ & $\begin{array}{c}\text { Elevation } \\
(\mathrm{m})\end{array}$ \\
\hline Damietta & 31.49 & 31.25 & 1.98 \\
\hline Alexandria & 29.57 & 31.12 & -1.78 \\
\hline Port Said & 32.14 & 31.17 & 0.80 \\
\hline MarsaMatruh & 27.13 & 31.20 & 25.00 \\
\hline Ismailia & 32.14 & 30.35 & 11.54 \\
\hline Mansura & 31.27 & 31.00 & 4.25 \\
\hline Tanta & 31.00 & 30.49 & 6.40 \\
\hline Banha & 31.18 & 30.46 & 45.00 \\
\hline Cairo & 31.24 & 30.80 & 64.12 \\
\hline Siwa & 25.19 & 29.12 & 15.00 \\
\hline BeniSuef & 30.01 & 29.12 & 32.40 \\
\hline Sharm El-Sheikh & 34.23 & 27.58 & 53.87 \\
\hline Safaga & 33.93 & 26.78 & 52.00 \\
\hline Qena & 32.43 & 26.10 & 77.72 \\
\hline Luxor & 32.42 & 25.40 & 83.25 \\
\hline Aswan & 23.58 & 32.47 & 194.23 \\
\hline Table & & & \\
\hline
\end{tabular}

Table 1 presents the latitude, longitude, and elevation of the climatic locations. A summary of the mean annual air 
temperature, wind speed, cumulative precipitation, sunshine, and relative humidity is given in Table 2. Data in this table shows no significant change in the mean annual air temperature and mean annual percent sunshine from climatic location to the other. On the other hand, the mean annual wind speed, mean annual cumulative precipitation, and mean annual relative humidity differ significantly from one climatic location to the other. Figure 3 and 4 show a comparison of minimum, average, and maximum air temperature at the selected weather stations during the months of January and August, respectively. The monthly standard deviation (S.D) of the air temperature is also shown on these figures. Moreover, Figure 5 shows a comparison of the mean monthly air temperatures at the selected climatic locations. These figures show that the Egyptian climate is very hot during the summer and worm during the winter. They also show the variation in the temperatures from north to south and east to west as well as coastal areas.

Table 2. Summary of the mean annual climatic data for the Selected Weather Stations in Egypt

\begin{tabular}{|c|c|c|c|c|c|}
\hline \multirow{2}{*}{ Weather Station } & \multicolumn{5}{|c|}{ Mean Annual Values } \\
\cline { 2 - 6 } & $\begin{array}{c}\mathrm{T} \\
\left({ }^{\circ} \mathrm{C}\right)\end{array}$ & $\begin{array}{c}\mathrm{S} \\
(\mathrm{km} / \mathrm{h})\end{array}$ & $\begin{array}{c}\text { SH } \\
(\%)\end{array}$ & $\begin{array}{c}\mathrm{CP} \\
(\mathrm{mm})\end{array}$ & $\begin{array}{c}\text { RH } \\
(\%)\end{array}$ \\
\hline Damietta & 21.84 & 13.56 & 88.76 & 220.0 & 66.81 \\
\hline Alexandria & 21.80 & 17.22 & 88.78 & 232.0 & 64.69 \\
\hline Port Said & 21.66 & 13.83 & 89.19 & 154.0 & 65.53 \\
\hline Marsa Matruh & 21.27 & 18.15 & 89.12 & 119.4 & 63.09 \\
\hline Ismailia & 22.2 & 8.97 & 87.91 & 37.5 & 54.31 \\
\hline Mansura & 22.45 & 6.77 & 81.29 & 101.6 & 62.19 \\
\hline Tanta & 21.88 & 8.38 & 84.99 & 95.3 & 59.39 \\
\hline Banha & 23.07 & 8.27 & 87.15 & 73.7 & 54.83 \\
\hline Cairo & 23.48 & 10.3 & 89.97 & 69.9 & 48.41 \\
\hline Siwa & 22.16 & 13.3 & 92.3 & 10.2 & 39.99 \\
\hline BeniSuef & 23.35 & 10.23 & 93.19 & 29.2 & 41.71 \\
\hline Sharm El- & 25.16 & 13.37 & 95.36 & 60.3 & 45.16 \\
\hline Sheikh & 24.35 & 13.84 & 95.67 & 45.7 & 45.74 \\
\hline Safaga & 23.10 & 8.41 & 95.67 & 34.9 & 33.11 \\
\hline Qena & 23.42 & 7.74 & 95.69 & 33.0 & 33.19 \\
\hline Luxor & 24.40 & 8.59 & 96.09 & 9.5 & 27.98 \\
\hline Aswan & & & &
\end{tabular}

Where:

$\mathrm{T}$ : mean aannual air Ttemperature $\left({ }^{\circ} \mathrm{C}\right)$

$\mathrm{S}$ : mean annual wind speed $(\mathrm{km} / \mathrm{h})$

SH: mean annual sun shine (\%)

$\mathrm{CP}$ : mean annual cumulative precipitation (mm)

$\mathrm{RH}$ : mean annual relative hhumidity (\%)

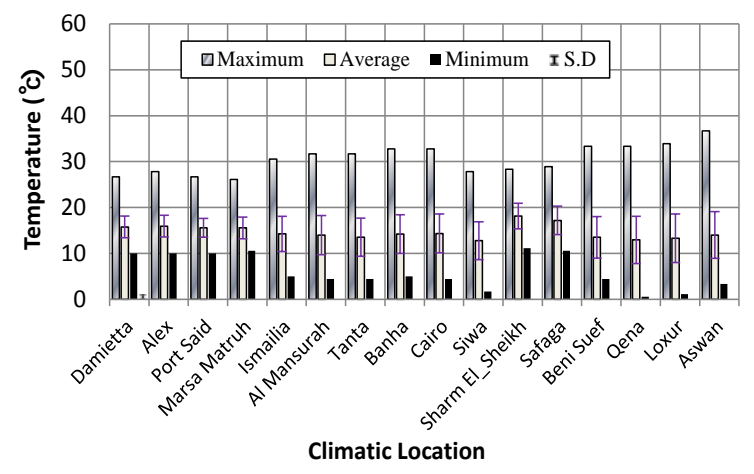

Figure 3. Comparison of minimum, average, maximum air temperatures and standard deviation during January

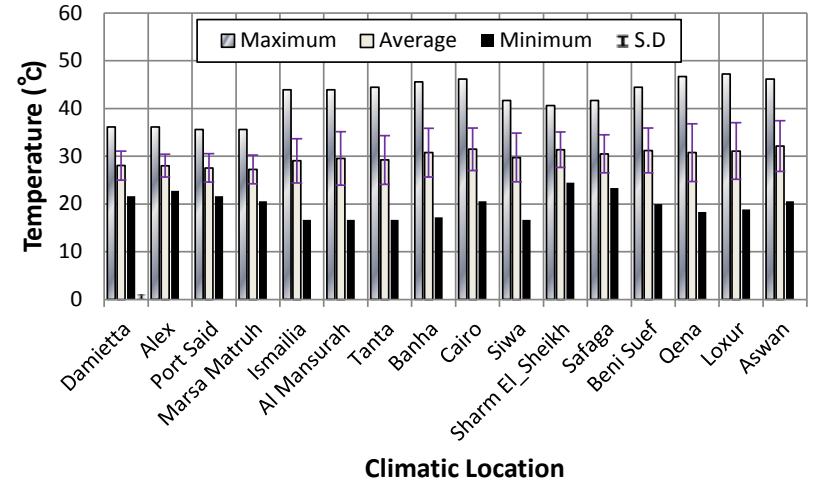

Figure 4. Comparison of minimum, average, maximum air temperatures and standard deviation during August

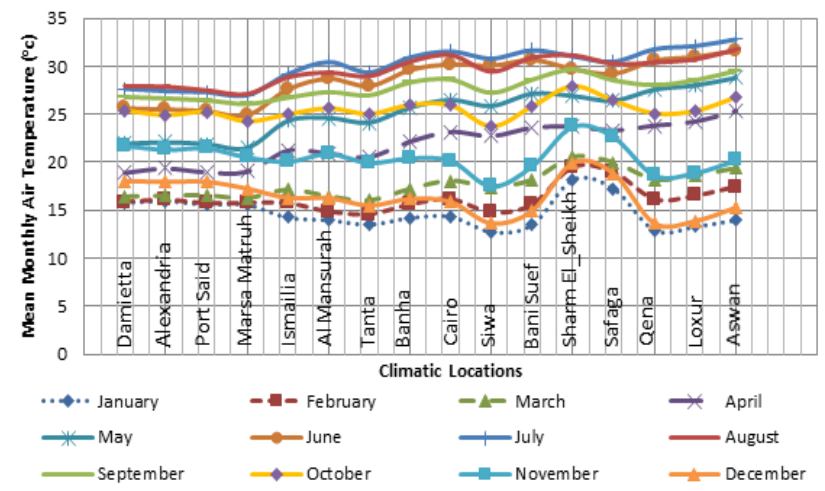

Figure 5. Comparison of mean monthly air temperatures at the selected environmental locations

\subsection{Linear Interpolation for Missing Climatic Data}

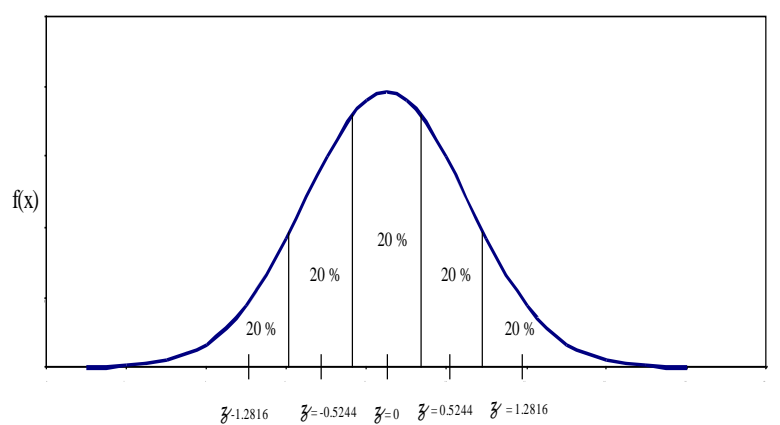

Figure 6. Temperature distribution for a given analysis period [3]

As previously mentioned, it was necessary to use interpolation in order to find out the hourly climatic data from the collected data which was every 3 hours. The interpolation used to find out the missing data within each three hours is not expected to produce significant errors. The reason for that is the methodology used by the Pavement ME Design method to process the climatic data for stress/strain/deformation computations. Instead of using the hourly climatic data, Pavement ME Design divides the processed temperature from the EICM at the mid-depth of each layer/sublayer over a given interval into five sub-seasons [3]. For each sub-season, the sub-layer temperature is defined by a temperature that represents $20 \%$ of the frequency distribution of the pavement temperature. The frequency distribution of the temperature is assumed to be normally distributed as shown in Figure 
5. The program then uses these five $20 \%$ quintile temperature to calculate the asphalt modulus at the mid depth of each asphalt concrete (AC) sublayer. For the unbound layers and subgrade soils, the program uses a monthly or semi-monthly temperature (if the pavement is exposed to freeze and thaw cycles) to compute the modulus. In addition, a recently published study concluded that the MEPDG predicted performance was not significantly affected when average daily climatic data was used instead of actual hourly climatic data [15].

Moreover, a mini study was conducted to assess the accuracy of the developed hourly data using the simple interpolation method. In this study a typical flexible pavement section with the properties explained in section 5 of this paper was used. The MEPDG was run with the inputs explained in section 5 using the developed hourly climatic data (temperature, relative humidity, sunshine, wind speed, and perception) for three weather stations.
These stations are Alexandria, Cairo, and Aswan, which represent different climatic conditions. The MEPDG was run again using the average daily weather data throughout the service life instead of the hourly data. The pavement performance as predicted by the MEPDG after 20 years of service life was compared. Table 3 summarizes the MEPDG predicted performance in terms of IRI, longitudinal cracking, alligator fatigue cracking, AC rutting, and total rutting predicted using the two different weather data at the selected climatic locations. For all practical purposes, the predicted performance reflects no significant change. This indicates than even the use of average daily climatic data instead of the hourly data as required by the MEPDG, did not have a significant effect on the predicted performance. Thus, the simple linear interpolation method used to provide the missing hourly data is not expected to yield significant errors in the MEPDG predicted performance.

Table 3. Comparison of MEPDG predicted performance using hourly and average daily climatic data

\begin{tabular}{|c|c|c|c|c|c|c|}
\hline Weather Station & Weather Data & IRI (m/km) & Longitudinal Cracking (m/km) & Alligator Cracking (\%) & AC Rut $(\mathrm{cm})$ & Total Rut $(\mathrm{cm})$ \\
\hline \multirow{2}{*}{ Alex. } & Hourly & 2.058 & 332.3 & 21.6 & 1.25 & 2.29 \\
\hline & Daily Average & 2.075 & 350.6 & 22.2 & 1.28 & 2.31 \\
\hline \multirow{2}{*}{ Cairo } & Hourly & 2.208 & 289.5 & 21.8 & 1.98 & 3.02 \\
\hline & Daily Average & 2.277 & 309.9 & 22.7 & 2.13 & 3.18 \\
\hline \multirow{2}{*}{ Aswan } & Hourly & 2.247 & 275.2 & 21.9 & 2.31 & 3.37 \\
\hline & Daily Average & 2.265 & 281.3 & 22.6 & 2.39 & 3.45 \\
\hline
\end{tabular}

\section{Influence of Climatic Data on Predicted Performance}

In order to assess the influence of the change in climatic data on ME Design predicted performance, a sensitivity study was conducted. In this study, a typical flexible pavement section consists of a $5 \mathrm{~cm}$ AC wearing surface [air voids $\left(\mathrm{V}_{\mathrm{a}}\right)=7 \%$, effective binder content $\left(\mathrm{V}_{\text {beff }}\right)=11.0 \%$, pen 60-70 asphalt binder], $6 \mathrm{~cm}$ AC binder course layer ( $\mathrm{V}_{\mathrm{a}}=8 \%, \mathrm{~V}_{\text {beff }}=10.2 \%$, pen $60-70$ asphalt binder), $25 \mathrm{~cm}$ aggregate base course layer (resilient modulus; $M_{r}=290$ $\mathrm{MPa})$ resting on a subgrade soil $\left(\mathrm{M}_{\mathrm{r}}=100 \mathrm{MPa}\right)$ was used in the analysis. The pavement cross section is shown in Figure 7. Level 3 traffic inputs were used in all simulation runs [annual average daily truck traffic (AADTT) in the design lane $=1100$, speed $=45 \mathrm{mph}$, truck traffic classification TTC11]. All other traffic related inputs were set to MEPDG default values.

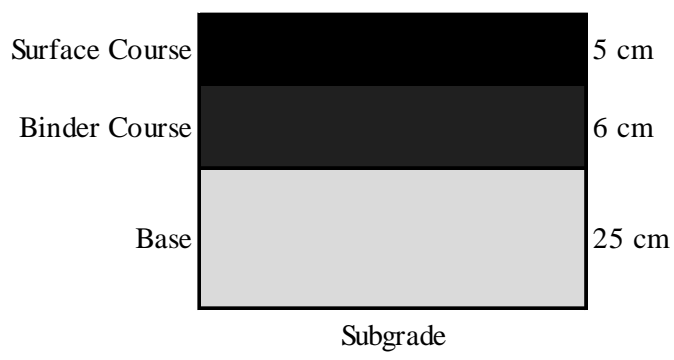

Figure 7. The typical flexible pavement cross section used in the sensitivity study

All input parameters such as traffic, ground water table depth, and material properties were kept constant. Only the climatic data was varied using the 16 developed climatic data files for Egypt. The MEPDG software was used to perform the simulation runs instead of the AASHTOWare Pavement ME Design. Both software are expected to yield the same results since they are both using the same performance models and computational techniques. All simulation runs were conducted for an analysis period of 20 years. The total number of computer simulation runs performed were 16 .

\section{Results and Analysis}

MEPDG predicted performance at the end of the service life in terms of AC rutting, total pavement rutting, bottom-up alligator fatigue cracking, top-down longitudinal fatigue cracking, and International Roughness Index (IRI) were compared for each climatic location. Figs 8- 12 present the influence of the climatic data on the MEPDG predicted AC rutting, total pavement rutting, alligator cracking, longitudinal cracking, and IRI, respectively. Because temperature varies significantly across Egypt especially from north to south as well as east to west, the AC rutting and hence total rutting was significantly affected by the climatic location. This is clearly shown in Figs 8 and 9. As the temperature increases, the AC rutting also increases. This figure shows that based on AC rutting, Egypt can be divided into three environmental locations (North, Middle, and South). The northern part has mild climate and thus low AC rutting, the middle part has moderate climate and thus moderate AC rutting, while the south part has a very hot climate and thus high AC rutting. Figure 10 shows that the predicted amounts of alligator fatigue cracks are very similar for the different climatic sites. There was little variation in the predicted longitudinal cracks from climatic site to another as shown in Figure 11. The reason for the low influence of the climatic data on the predicted cracks is the worm climate of Egypt even during the winter months. Cracks are usually affected by the colder temperature rather than the higher temperatures as the modulus of the AC layers gets stiffer at colder temperatures. Since IRI is a function 
of the predicted distresses especially the predicted cracks, the IRI was not significantly affected by the change in climatic locations. This is obvious in Figure 12. It should be noted that if a flexible pavement system is designed using the AASHTO 1993 guide, it would result in the same design even if the climatic data was varied.

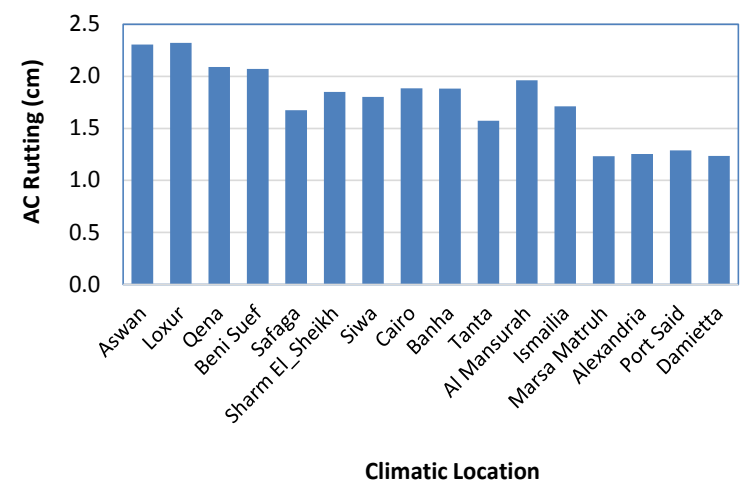

Figure 8. Predicted AC rutting at the investigated weather stations

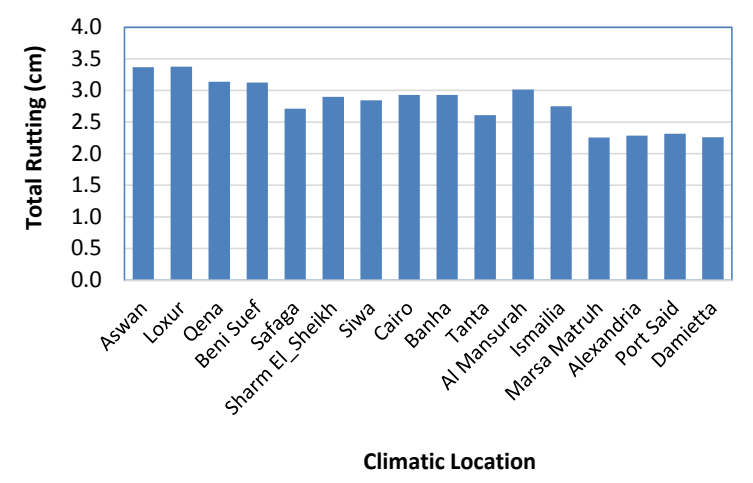

Figure 9. Predicted total rutting at the investigated weather stations

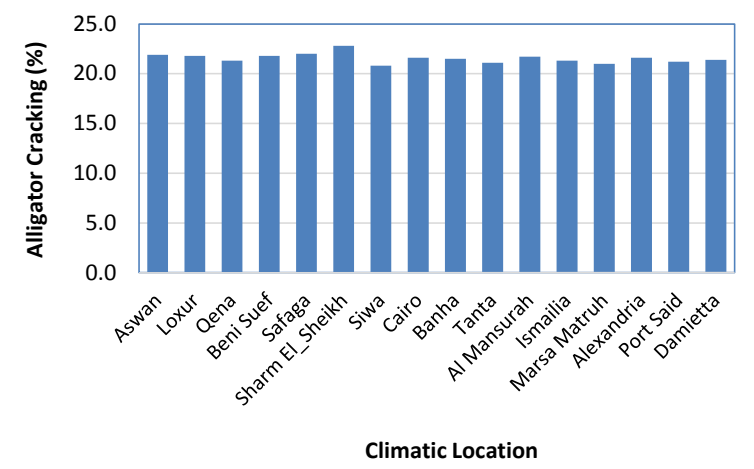

Figure 10. Predicted alligator cracking at the investigated weather stations

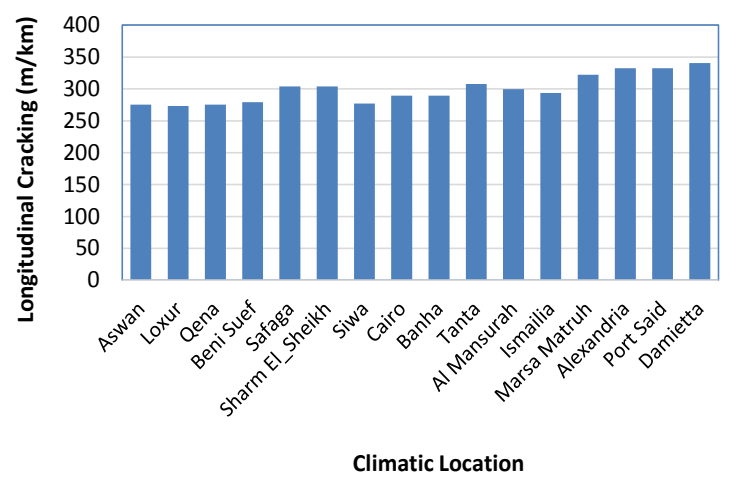

Figure 11. Predicted longitudinal cracking at the investigated weather stations

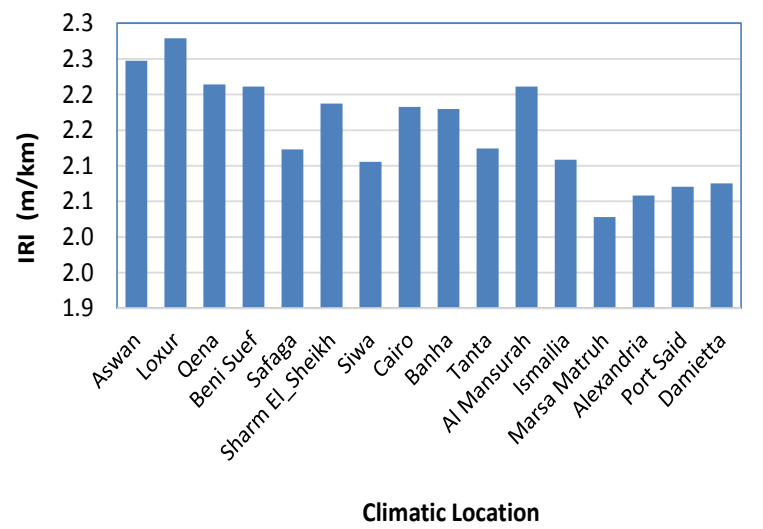

Figure 12. Predicted IRI at the investigated weather stations

\section{Summary and Conclusions}

A total of 16 climatic data files covering the populated areas in Egypt were developed. These climatic data are ready to be used with the AASHTOWare ME design. Simple linear interpolation was used to compute the missing hourly climatic data. A conducted mini study showed that converting the climatic data from hourly data into 5 quintiles every month significantly reduces the sensitivity of MEPDG predicted distresses to the actual hourly climatic data. For all practical purposes, the MEPDG predicted performance using the hourly climatic data was not significantly different from the performance predicted using average daily climatic data. A typical flexible pavement section was simulated using the MEPDG at the 16 different climatic locations and the performance predicted using MEPDG was analyzed. The performance indicators predicted by MEPDG are rutting, alligator fatigue cracking, longitudinal cracking, thermal cracking, and IRI. Results of the simulation runs showed the following:

1. Pavement performance was significantly affected by the change in the climatic data. As expected, for Egypt, the most significant influence was on the predicted rutting of the asphalt layer. The hotter the area is the higher the predicted AC rutting and hence total rutting.

2. Based on AC rutting, Egypt can be divided into three environmental locations (North, Middle, and South). The northern part has mild climate and thus low AC rutting, the middle part has moderate climate and thus moderate AC rutting, while the south part has a very hot climate and thus high AC rutting.

3. No significant change in the predicted alligator fatigue cracking at the different climatic locations was found.

4. Longitudinal Cracking was found to be affected by the change in the climatic location. However the influence is minor.

5. Since IRI is a function of predicted distresses especially cracking, no significant change in the predicted IRI at the different climatic locations was found.

\section{References}

[1] Li, Q., Mills, L., McNeil, S., and Attoh-Okine, N., (2012) "Exploring the Impact of Climate Change On Pavement 
Performance And Design," Presented at the Transportation Research Board 91st Annual Meeting.

[2] Huang, Y. H. (2004), Pavement Analysis and Design, Gourshetty Raju, 2004, Second Edition, Pearson Prentice Hall, Upper Saddle River, NJ 07458.

[3] ARA, Inc., ERES Consultants Division. (2004). "Guide for Mechanistic-Empirical Design of New and Rehabilitated Pavement Structures, NCHRP 1-37A Final Report,” ERES Consultants Division, Transportation research Board, National Research Council, Washington, D.C.

[4] American Association of State Highways and Transportation Officials, (2008). Mechanistic-Empirical Pavement Design Guide: A Manual of Practice. Interim Edition, Washington, D.C. American Association of Highways and Transportation Officials.

[5] Bayomy, F., El-Badawy, S., and Awed, A., May. 2012. "Implementation of the MEPDG for Flexible Pavements in Idaho," (Report No. FHWA-ID-12-193). ITD Project RP 193, NIATT Project KLK557. National Institute for Advanced Transportation Technology, University of Idaho, Moscow, Idaho: U.S.

[6] Saha, J., Nassiri S., Bayat, A., and Soleymani, H., "Evaluation of the Effects of Canadian Climate Conditions on the MEPDG Predictions for Flexible Pavement Performance," International Journal of Pavement Engineering, 15 (5). 392-401. May. 2014

[7] Meagher, W., Daniel, J. S., Jacobs, J., and Linder E., " Method for Evaluating Implications of Climate Change for Design and Performance of Flexible Pavements," Transportation Research Board of the National Academies, 2 (2305). 111-120. 2012

[8] Byram, D., Xiao, D. X., Wang, K., C. P., and Hall, Kevin, (2012). "Sensitivity Analysis of Climatic Influence on MEPDG Flexible Pavement Performance Predictions," Transportation Research Board 91st Annual Meeting Compendium of Papers DVD, TRB, The National Academies, Washington, DC.

[9] Zaghloul, S., Ayed, A., AbdEl Halim, A., Vitillo N., and Sauber R."Investigations of Environmental and Traffic Impacts on Mechanistic-Empirical Pavement Design Guide Predictions," Transportation Research Board of the National Academies, (1967). 148-159. 2006.

[10] Darter, M., L. Titus-Glover, and H., Von Quintus. Implementation of the Mechanistic-Empirical Pavement Design Guide in Utah: Validation, Calibration, and Development of the UDOT MEPDG
User’s Guide. Report No. UT-09.11, Applied Research Associates, Inc., 2009.

[11] Von Quintus, H. and J. Moulthrop. Mechanistic-Empirical Pavement Design Guide Flexible Pavement Performance Prediction Models for Montana: Volume I Executive Research Summary. FHWA/MT-07-008/8158-1 Final Report, 2007.

[12] Souliman, M. Calibration of the AASHTO MEPDG for Flexible Pavements for Arizona Conditions. Tempe, AZ: Arizona State University, Master's Thesis, 2009.

[13] Li, J., L. Pierce, and J. Uhlmeryer. "Calibration of Flexible Pavement in Mechanistic-Empirical Pavement Design Guide for Washington State.” Transportation Research Record, Journal of the Transportation Research Board, No. 2095 (2009): 73-83.

[14] Ley Y., Kadam, S., Frazier, R., Robertson, B., and Riding, K. "Development and Implementation of a Mechanistic and Empirical Pavement Design Guide (MEPDG) for Rigid Pavements," Annual Report for FY 2009, ODOT SPR Item Number 2208, 2009.

[15] Delgadillo, R., Wahr, C., Garcia, G., Osorio, L., and Salfate, O. (2014)"Generating Hourly Climatic Data from Available Weather Information for Pavement Design," Presented at the Annual Meeting of the Transportation Research Board.

[16] Dezotepe, G., and Ksaibati, K., "The Effect of Environmental Factors on the Implementation of the Mechanistic-Empirical Pavement Design Guide," Wyoming Technology Transfer Center, 2011.

[17] Breakah, T., Williams, R., Herzmann, D., and Takle, E.,’Effects of Using Accurate Climatic Conditions for Mechanistic-Empirical Pavement Design,” J. Transp. Eng., 137 (1), 2011, pp. 84-90.

[18] Heitzman, M., Timm, D., Herzmann, D., Takle, G., and Traux, D. (2011). "Developing MEPDG Climate Data Input Files for Mississippi," FHWA/MS-RD- DOT-11-232 Final Report, Department of Civil and Environmental Engineering, Mississippi State University, Mississippi State, MS 38762-9546.

[19] Egyptian Meteorological Authority: http://ema.gov.eg, Accessed September 2013.

[20] World Weather Online: http://www.worldweatheronline.com, Accessed January 2014. 